\title{
Functionalization of Amberlite XAD-4 with 8-hydroxyquinoline chelator using aryldiazonium radical reaction and its application for solid phase extraction of trace metals from groundwater samples
}

\author{
AlHarbi H.N. and AlSuhaimi A.O.* \\ Chemistry Department, Faculty of Science, Taibah University, Prince Nayef Road, P.O. Box 344, AlMedianh AIMunawarah 42353, Saudi \\ Arabia \\ Received: 18/06/2019, Accepted: 13/09/2020, Available online: 14/09/2020 \\ *to whom all correspondence should be addressed: e-mail: asuhaimi@taiabhu.edu.sa \\ https://doi.org/10.30955/gni.003165
}

\section{Graphical abstract}

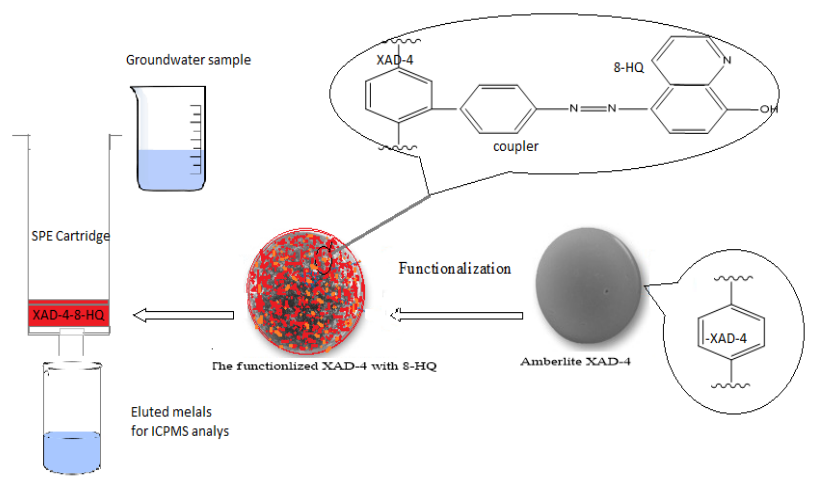

Keywords: Solid phase extraction, Amberlite XAD-4, chelating resin, trace metals, ICP-MS, and groundwater.

\section{Introduction}

Heavy metals (HMs) are categorized as extremely toxic environmental pollutants (Srivastava and Goyal, 2010). They occur as natural constituents of earth crust, but many anthropogenic process accompanying the steadily growth of urbanization activities have increased the amount of heavy metals deposited onto earth surface several times above the background level from natural sources (Khan et al., 2011). HMs possess crucial hazardous effects to biota, animal, and human being because of their toxicity, bioaccumulative and non-biodegradable nature (Bazrafshan et al., 2015; Lichtfouse et al., 2013). Frequently, HMs exist within very complex matrices at sufficiently low levels. Therefore, their accurate quantification is a challenging analytical task (Brown and Milton, 2005).

The truthful determination of trace analytes in distinct sample matrices is always a central objective for any analytical procedure, however, most of the available analytical techniques do not enable direct analysis. Therefore, an appropriate sample pretreatment step is usually required to separate the analytes from the matrix and preconcentrate them before their determination ( $\mathrm{Hu}$ and He, 2012; Liu et al., 2007; Wang et al., 2003).

There are many procedures based on various separation concepts to separate trace elements from accompanying interferences. The choice of the suitable method depends on certain distinctive parameters including sample nature, concentrations of the analytes and the analytical techniques to be used in final measurement determine the adequate sample preparation method (Liu et al., 2004). Examples of the common separation/extraction methods are; coprecipitation (Mendil et al., 2015), ion exchange (Dabrowski et al., 2004), electro-deposition (Armstrong et al., 1996), cloud point extraction (Shemirani and Yousefi, 
2007), membrane filtration (Soylak et al., 2007), solid phase extraction (SPE) (sometimes referred to as liquidsolid extraction) (Nickerson, 2011), adsorption (Liu et al., 2007) and liquid-liquid extraction (LLE) (Korn et al., 2006).

Among the numerous extraction and enrichment methods, SPE has become one of the most efficient multielement pre-concentration process for wide range of organic and inorganic analytes (Dabrowski, 1998; Huck and Bonn, 2000). Perhaps because SPE offers many advantages such as high recovery, short extraction time, low cost, simplicity and low consumption (or none) of organic solvents (Golshaei et al., 2015; Liu et al., 2007).

The ever continues research efforts in SPE provided science community with wide variety of (selective) SPE materials. Regularly, these materials prepared either by physical modifications (impregnation) or chemical modifications (chemical binding of selected moieties e.g., chelating agents for metals) to various solid supports, such as activated carbon, alumina, cellulose, silica gel, polyacrylate polymer and XAD resins, are useful substrates for the synthesis of SPE materials (Zhai et al., 2010)

The commercially available Amberlite resins are very promising substrate for the design of chelating matrices due to their characteristic physical and chemical properties such as high surface area, porosity, purity and durability (Ahmad et al., 2015). The well-known member of Amberlite XAD series; Amberlite XAD-4 which is a porous acrosslinked polystyrene divinylbenzene polymer, has found immense applications for the enrichment/separation of trace metals ions (Uzun et al., 2001). Amberlite XAD resins have attracted much attention of researchers in the last few years for their appropriateness to be functionalized with broad range of specific chelating moieties.

The chelated resins showed good performance as SPE for preconcentration metal ions from various matrices in various applications (Gao et al., 2010). Noticeably, most of the published chemical modification methods were based on the nitration step of phenyl ring with sulfuric and nitric acids followed by a diazo-coupling reaction (Jung et al., 2010; Saxena and Meena, 2014).

The recently introduced chemical modification that uses the radical addition of aryldiazonium salts in presence of hypophosphorous acid as catalyst, is a very convenient approach for the addition of reactive functional group to the surface of carbon and other substrates. The obtained intermediate from radical addition reaction is amenable for the attachment of many moieties utilizing various chemical transformations like azo coupling scheme (Pandurangappa and Raghu, 2011).

Oxin chelating agents are very useful in analytical chemistry and radiochemistry applications, mainly for the extraction and fluorometric spectrophotometric determination of metal ions (Kosa et al., 2012). 8-Hydroxyquinoline (8-HQ) is the most popular oxin chelators due to its capability to form stable complexes with many metal ions. 8-HQ and its derivatives are among the early chelating moieties that being successfully employed in the synthesis of chelating resins, due to their preferable chelating capacity for wide range of transition and heavy metals over alkaline earth cations (Wegscheider and Knapp, 1981).

A previous work in our laboratory showed that the chemical reduction of aryldiazonium salts method was a reliable approach for the covalent attachment of 8-HO onto activated carbon (Alqadhi and Alsuhaimi, 2020). In this work, the method was proposed as green chemistry process for the chemical attachment of 8-HQ chelator onto amberlite XAD-4 substrate. The performance of synthesized metal chelator as SPE materials for sample preparation of trace metals from groundwater samples has been optimized.

\section{Experimental work}

\subsection{Chemical reagents}

All chemicals used in this work were of analytical reagentgrade and all working solutions were prepared in Millipore water $(\leq 18.2 \Omega)$. The solid support Amberlite XAD-4 (polystyrene divinylbenzene type, bead size 20-60 mesh and surface area of $750 \mathrm{~m}^{2} / \mathrm{g}$ ) were purchased from SigmaAldrich chemie $\mathrm{GmbH}$ (Darmstadt, Germany). The 4nitroaniline, sodium hydrosulfite $\left(\mathrm{Na}_{2} \mathrm{~S}_{2} \mathrm{O}_{4}\right), 8$ Hydroxyquinoline and hypophosphorous acid were obtained from Acros Organics (Geel, Belgium), Sodium Nitrite $\left(\mathrm{NaNO}_{2}\right)$ was purchased from Loba Chemie (Mumbai, India). Hydrochloric acid and nitric acid from Panreac Quimica, SA (Barcelona, Spain) and ethanol from Fisher Scientific (Loughborough, UK).

Metals standard solutions were prepared from Elemental stock solutions $1 \mathrm{mg} / \mathrm{ml}$, Acros Organics (Geel, Belgium) by proper dilution. Ammonium acetate purchased from Sigma-Aldrich chemie GmbH (Darmstadt, Germany), buffer was prepared from ammonium acetate and purified by passing through a column of Chelex-100 from Bio-Rad (Hercules, CA, USA). The $\mathrm{pH}$ was adjusted to the required values with nitric acid, acetic acid from Sigma Aldrich (Darmstadt, Germany) or liquid ammonia from Panreac (Barcelona, Spain). Ultrapure water produced with a Millipore Milli-Q water purification system (Darmstadt, Germany). All the glassware which used in the experiments were soaked overnight into a $5 \%(\mathrm{v} / \mathrm{v})$ nitric acid solution and rinsed thoroughly with purified water before usage.

\subsection{Instrumentation and measurements}

ICP-MS 7500 series, Agilent Technologies (Santa Clara, California, USA) was used for the determination of metal ions. The instrument preset at the standard operating parameters recommended by manufacturer. The $\mathrm{pH}$ measurements were done using a Basis pH meter $\mathrm{HI} 2211$ pH/ORP meter (HANNA Instrument Company, Carrollton, Texas, USA).

IR spectra were recorded in the range of $400-4000 \mathrm{~cm}^{-1}$ using Thermo NICOLET 380 FTIR equipped with attenuated total reflection (ATR) accessory (Thermo-Fisher Scientific, Waltham, Massachusetts, USA). X-Ray photoelectron spectroscopy (XPS) for C1s, N1s and O1s were performed on CAE: Pass Energy $150.0 \mathrm{eV}$ (Thermo Scientific, Waltham, Massachusetts, USA) equipped with AI K Alpha with a step size of $1 \mathrm{eV}$. Thermogravimetric analysis (TGA) was carried 
out under nitrogen atmosphere at a heating rate $10^{\circ} \mathrm{C} / \mathrm{min}$ using TA instrument, model SDT Q600, (Tokyo, Japan).

\subsection{Preparation of 8-HQ-amberlite XAD-4 Chelating Resin}

The 8-HQ-amberlite XAD-4 chelating resin was prepared using a simple three- step chemical transformation as shown follows:

Firstly, the 4-nitroaniline diazonium salt radical was generated in situ by dissolving $2 \mathrm{~g}$ of 4-nitroaniline into 50 $\mathrm{ml} \mathrm{1:1} \mathrm{solution} \mathrm{of} \mathrm{HCl}$ : water. The solution was cooled in ice-bath and a cold solution of $2 \mathrm{~g} \mathrm{NaNO}_{2}$ dissolved in water was added dropwise with continues stirring (Saylam et al., 2014). Then a $20 \mathrm{~g}$ of amberlite XAD-4 was added and a 50 $\mathrm{ml}$ of hypophosphorous acid $\left(\mathrm{H}_{3} \mathrm{PO}_{2}, 50 \% \mathrm{~V} / \mathrm{V}\right.$ in water) solution was added slowly. The solution was stirred at $0-5{ }^{\circ} \mathrm{C}$ for $2 \mathrm{~h}$. Then, filtered, washed with deionized water to remove any excess acid and finally washed with acetone to clean the product from any residual diazonium salt molecules. The functionalized XAD-4 was then vacuum dried for $24 \mathrm{~h}$ before being used in the subsequent stage (Abiman et al., 2008; Kempegowda and Malingappa, 2013; Wildgoose et al., 2005).

In second step nitro groups on the surface of XAD-4 was reduced using $50 \mathrm{ml}$ solution of $5 \%$ sodium hydrosulfite $\left(\mathrm{Na}_{2} \mathrm{~S}_{2} \mathrm{O}_{4}\right)$ in a sealed flask at $45{ }^{\circ} \mathrm{C}$ for $24 \mathrm{~h}$ to insure a maximum conversion of $\left(-\mathrm{NO}_{2}\right)$ groups into $\left(-\mathrm{NH}_{2}\right)$ groups. The product was filtered and washed with cold water to remove any excess of salt and used in the diazocoupling step (Fan et al., 2007; Scheuerman and Tumelty, 2000).

In third step, the aminobenzyl-XAD-4 was diazotized for $1.5 \mathrm{~h}$ at $0-5{ }^{\circ} \mathrm{C}$ with $50 \mathrm{ml}$ of $2 \%(\mathrm{w} / \mathrm{v}) \mathrm{NaNO}_{2}$ in $1 \%$ acetic acid solution. Then filtered immediately, washed with cold water and a $50 \mathrm{ml}$ of $1 \% 8-\mathrm{HQ}$ solution in ethanol was added dropwise to the mixture for $4 \mathrm{~h}$ with frequent mechanical shaking to allow the diazicoupling reaction to complete.

The obtained resin was filtered, washed with ethanol, water, $2 \% \mathrm{HCl}$ solution and water until the filtrate showed no characteristic color. The chelator was then vacuum dried and stored in desiccator till the subsequent use (Fan et al., 2007).

\subsection{Chelator sorption performance}

In order to evaluate the sorption capability of the synthesized metal chelator, it has been used a SPE sorbent for $\mathrm{Co}, \mathrm{Ni}$ and $\mathrm{Cu}$ from standard solutions and groundwater real samples. These metal ions were chosen as a prove of concept.

\subsection{Sorption capacity study}

The sorption capacity (maximum amount of metal adsorbed per gram) of the prepared chelator; AXAD-4-8HQ was determined for $\mathrm{Co}, \mathrm{Ni}$ and $\mathrm{Cu}$ in batch mode experiment.

This test was performed by placing $0.25 \mathrm{~g}$ of dry resin into $50 \mathrm{ml}$ conical flask and $10 \mathrm{ml}$ of $100 \mathrm{mg} / \mathrm{L}$ solution of each metal prepared in ammonium acetate buffer $(0.2 \mathrm{M}, \mathrm{pH} 6)$ was added. The mixture was left to equilibrate overnight over a mechanical shaker. The solution was centrifuged and the amount of the remained metal ions in the supernatant solution were quantified against the original concentration using ICP-MS.

\subsection{Effect of solution $\mathrm{pH}$}

The optimum $\mathrm{pH}$ of metal ion uptake was determined by static batch experiment. Briefly, $0.1 \mathrm{~g}$ of the dry chelated AXAD-4-8HQ resin was suspended into $10 \mathrm{ml}$ of mlutielements solutions containing $100 \mathrm{ng} / \mathrm{ml}$ of $\mathrm{Co}, \mathrm{Ni}$ and $\mathrm{Cu}$ in $0.2 \mathrm{M}$ ammonium acetate solution. The $\mathrm{pH}$ of the metal ions solution was adjusted prior to equilibration over a range $(\mathrm{pH} 2-10)$ with nitric acid $(0.1 \mathrm{M})$, acetic acid $(0.1 \mathrm{M})$ or ammonia $(0.1 \mathrm{M})$. The solutions were then centrifuged, and the residual metal concentration of the supernatant was measured versus the original concentration using ICPMS. All experiments were performed in triplicate (AISuhaimi et al., 2017; Islam et al., 2010).

\subsection{Effect of contact time}

The potential of this parameter was investigated for the sorption of metal ions; $\mathrm{Co}, \mathrm{Ni}$ and $\mathrm{Cu}$ as a function of time in batch mode experiment. Briefly, the synthesized AXAD4-8HQ resin $(0.1 \mathrm{gm})$ was agitated with $100 \mathrm{ml}$ of solution containing $(100 \mathrm{ng} / \mathrm{ml})$ of the tested metal ions and left to equilibrate for different time intervals $(2,5,10,15,30,45$, 60,80 and $120 \mathrm{~min}$ ). The concentration of metal ions in the supernatant solution was determined by ICP-MS.

\subsection{SPE Manifold and procedure}

The dynamic SPE experiments conducted using a 12-way standard SPE manifold (Ato Science, China) operated with a vacuum pump (AP-9950; Ato Science, China). About 0.5g of the synthesized resin packed into SPE cartridges (bond straight barrel; Agilent Technologies) to make discs of 5 $\mathrm{mm}$ height sandwiched between a pair of porous Teflon filters. The SPE protocol performed according to the following sequences. Initially, the SPE cartridges were conditioned by passing $5 \mathrm{ml}$ of buffer solution at $1 \mathrm{ml} / \mathrm{min}$ flow rate and then $25 \mathrm{ml}$ of samples were loaded at 0.5 $\mathrm{ml} / \mathrm{min}$ flow rate. After that, the cartridges were flushed with $5 \mathrm{ml}$ of water (at $0.5 \mathrm{ml} / \mathrm{min}$ ) to remove any residual metals and matrices. Finally, the sequestered (chelated) metal ions were eluted with $2.5 \mathrm{ml}$ of $1.5 \mathrm{M} \mathrm{HNO}_{3}$ at a flow rate of $2 \mathrm{ml} / \mathrm{min}$. The eluted metals were collected into 10 $\mathrm{ml} \mathrm{PTFE} \mathrm{sample} \mathrm{tubes} \mathrm{and} \mathrm{diluted} \mathrm{with} 5 \mathrm{ml}$ Millipore water for ICP-MS analyses. This protocol has been used for all the standards and the real samples (Liu et al., 2014; Zhao et al., 2011)

\section{Results and discussion}

\subsection{Chemical modification reaction}

The attachment of 8-HQ chelating agent onto the surface of Amberlite XAD-4 was attained making use of a threestep chemical reaction as shown schematically in (Figure 1). In first step, 4-nitroaniline groups were covalently anchored onto Amberlite XAD-4 surface throughout the chemically activated one-electron reduction of the in-situ generated 4-nitrobenzenediazonium salt intermediate in the presence of hypophosphorous acid as a reducing catalyst. Meanwhile the second step involves the reduction of nitro groups into amines using sodium hydrosulfite $\left(\mathrm{Na}_{2} \mathrm{~S}_{2} \mathrm{O}_{4}\right)$. In the final step, the $8-\mathrm{HQ}$ moiety was coupled 
onto Amberlite XAD-4 via the classical diazo linkage (Abiman et al., 2008; Fan et al., 2007; Kempegowda and Malingappa, 2013; Scheuerman and Tumelty, 2000; Wildgoose et al., 2005).

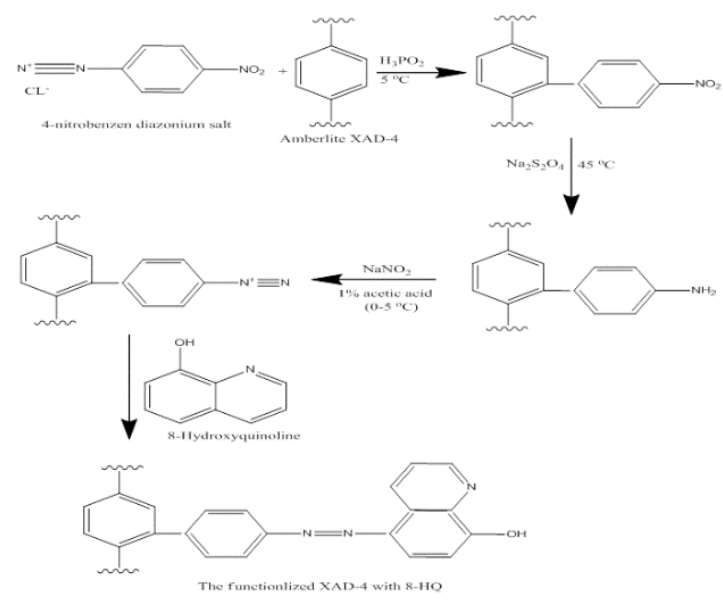

Figure 1. Reaction sequence of XAD-4 functionalization with 8$\mathrm{HQ}$

\subsection{Characterization of $A X A D 4-8 H Q$ resin}

\subsubsection{ATR-IR characterization}

The successfulness of AXAD4-8HQ resin synthesis has been confirmed by ATR-IR analysis. The IR spectrum of AXAD4$8 \mathrm{HQ}$ is compared with that of that of a plain Amberlite XAD4 (Figure 2). Obviously, few bands in the regions 1560-1345 $\mathrm{cm}^{-1}$ and $1250-500 \mathrm{~cm}^{-1}$ which are due to the plan resin, can be seen in both spectra. The linkage of 8-HQ moiety however can be recognized from many IR bands. These include, the appearance of the distinctive band at 3448.98 $\mathrm{cm}^{-1}$ in IR spectrum of the AXAD4-8HQ resin which belong to phenolic hydroxyl group (O-H), and the band at 2927.11 $\mathrm{cm}^{-1}$ that comes from $\mathrm{C}-\mathrm{H}$ (stretching). The existence of $\mathrm{C}=\mathrm{N}$ connection is clearly identified from the band around $1604.53 \mathrm{~cm}^{1}$.

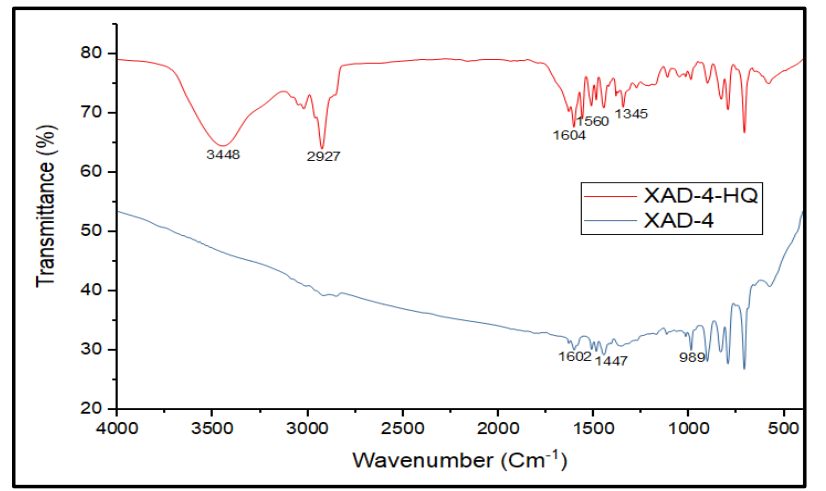

Figure 2. The IR spectrum of Amberlite XAD-4 and AXAD4-8HQ resin

The fingerprint peak at $1345.99 \mathrm{~cm}^{-1}$ confirmed the presence of C-N and that observed at $1560.39 \mathrm{~cm}^{-1}$ confirms the existence of $-\mathrm{N}=\mathrm{N}$-. This result indicates that the 8 - HQ moiety has been successfully immobilized onto
Amberlite XAD-4 surface through diazotized $\mathrm{N}=\mathrm{N}$ coupling (Cheira, 2015; Nezhati et al., 2010; Saxena and Meena, 2014).

\subsubsection{TGA characterization}

The TGA experiments were conducted for plain AXAD-4 and $A X A D-4-8 H Q$ resin at a heating rate of $10^{\circ} \mathrm{C} / \mathrm{min}$ from ambient temperature to $900{ }^{\circ} \mathrm{C}$ in flow of $\mathrm{N}_{2}$. The TGA curves for the bare AXAD-4 and AXAD-4-8HQ resin are represented in (Figure 3 ). The thermogram of plain AXAD4 polymer, exhibited clear mass degradation over the temperature range $320-895^{\circ} \mathrm{C}(100 \%)$. On the other hand, the TGA of chelating resin; AXAD-4-8HQ, displayed two step weight losses up to $645{ }^{\circ} \mathrm{C}$. The resin has lost about $12 \%$ of its original weight at $220-330{ }^{\circ} \mathrm{C}$ as a result of displacement of $8-\mathrm{HQ}$ moieties out of the polymer. The weight loss after $330{ }^{\circ} \mathrm{C}(88 \%)$ could be associated to the dissociation of polymeric matrix (Gladis and Rao, 2002; Pacurariu et al., 2013).

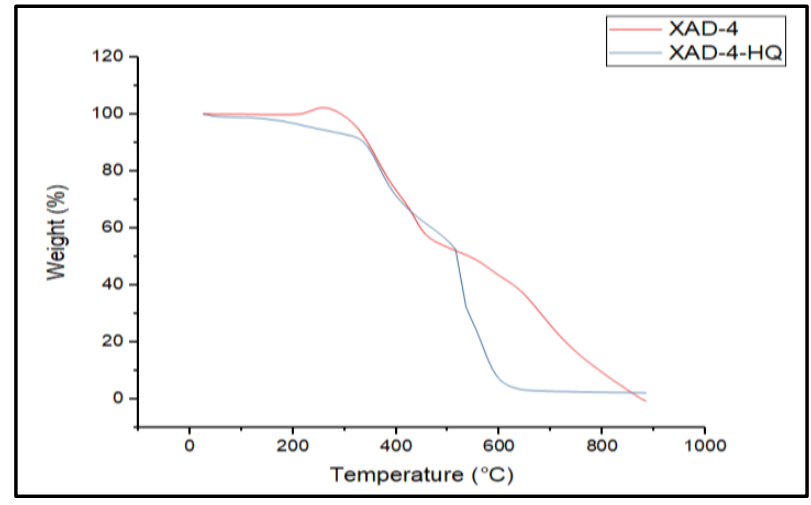

Figure 3. TGA Thermogram of AXAD-4 and AXAD-4-8HQ resin

\subsubsection{XPS characterization}

The chemical bonding of $8 \mathrm{HQ}$ moiety onto the AXAD4 surface has been ascertained using X-ray photoelectron spectroscopic (XPS) technique. XPS analysis is reliable approach to confirm the successfulness of modification of AXAD-4 with 8-HQ. The survey spectra of AXAD-4 and AXAD4-8HQ resin is shown in (Figure 4). It was clear from (Figure 4) that the XPS spectrum of AXAD4-8HQ showed peaks for N1s (two components peaks of pyridinic $\mathrm{N}$ at $398.08 \mathrm{eV}$ and $400.08 \mathrm{eV}$ corresponds to $(\mathrm{N}=\mathrm{N})$, which arose from the present of 8-HQ ligands and its linkage on the AXAD-4 surface. The clear existence of $\mathrm{N}$ (from the 8$\mathrm{HQ}$ ) from the spectrum strongly indicates that the 8-HQ molecule is covalently bonded to the AXAD-4 surface (Kosa et al., 2012). 
Table 1. Comparison of sorption capacity of the synthesised chelator with other 8-HQ-amberlite resins for Co, Ni, Cu metal ions.

\begin{tabular}{ccccc}
\hline \multirow{2}{*}{ Adsorbent } & \multicolumn{3}{c}{ Metal ions $(\mathbf{m M} / \mathbf{g})$} & Refs. \\
\cline { 2 - 5 } & Co & $\mathbf{N i}$ & $\mathbf{C u}$ & Lee et al. (1988) \\
\hline Amberlite XAD-7 & - & 0.011 & 0.018 & Duran et al. (2007) \\
\hline Amberlite XAD-2000* & 0.115 & 0.132 & 0.148 & Gundogdu et al. (2007) \\
\hline Amberlite XAD-2010* & 0.161 & 0.187 & 0.136 & Sadia et al. (2016) \\
\hline Amberlite IR-120* & - & - & 0.038 & Current work \\
\hline Amberlite XAD-4 & 0.366 & 0.265 & &
\end{tabular}

Table 2. Trace metals contents of real water samples with the proposed method (mean conc. \pm RSD ( $\mathrm{ng} \mathrm{ml} \mathrm{Pl}^{-1}$ ) Sample volume $25 \mathrm{ml}^{\text {, }}$ eluent $1.5 \mathrm{M} \mathrm{HNO}_{3}$

\begin{tabular}{|c|c|c|c|c|}
\hline Sample & Metals & Added (ng/ml) & Found + RSD (ng/ml) & Recovery (\%) \\
\hline \multirow[t]{6}{*}{1} & Co & 0 & $1.21 \pm 0.48$ & $96.4 \%$ \\
\hline & & 5 & $6.03 \pm 1.66$ & \\
\hline & $\mathrm{Ni}$ & 0 & $0.97 \pm 1.60$ & $97.82 \%$ \\
\hline & & 5 & $5.86 \pm 1.20$ & \\
\hline & $\mathrm{Cu}$ & 0 & $2.04 \pm 0.83$ & $105.41 \%$ \\
\hline & & 5 & $7.31 \pm 1.31$ & \\
\hline \multirow[t]{6}{*}{2} & Co & 0 & $1.24 \pm 1.37$ & $96.62 \%$ \\
\hline & & 5 & $6.07 \pm 1.29$ & \\
\hline & $\mathrm{Ni}$ & 0 & $1.12 \pm 0.98$ & $97.81 \%$ \\
\hline & & 5 & $6.01 \pm 1.76$ & \\
\hline & $\mathrm{Cu}$ & 0 & $1.97 \pm 0.56$ & $103.05 \%$ \\
\hline & & 5 & $7.12 \pm 1.97$ & \\
\hline \multirow[t]{6}{*}{3} & Co & 0 & $1.15 \pm 0.9 /$ & $98.81 \%$ \\
\hline & & 5 & $6.09 \pm 1.28$ & \\
\hline & $\mathrm{Ni}$ & 0 & $0.95 \pm 1.16$ & $99.20 \%$ \\
\hline & & 5 & $5.91 \pm 1.86$ & \\
\hline & $\mathrm{Cu}$ & 0 & $2.27 \pm 0.88$ & $97.81 \%$ \\
\hline & & 5 & $7.16 \pm 1.08$ & \\
\hline \multirow[t]{6}{*}{4} & Co & 0 & $1.17 \pm 0.94$ & $98.04 \%$ \\
\hline & & 5 & $6.07 \pm 1.18$ & \\
\hline & $\mathrm{Ni}$ & 0 & $1.03 \pm 1.65$ & $99.61 \%$ \\
\hline & & 5 & $6.01 \pm 1.10$ & \\
\hline & $\mathrm{Cu}$ & 0 & $2.15 \pm 0.47$ & $94.41 \%$ \\
\hline & & 5 & $6.87 \pm 1.167$ & \\
\hline \multirow[t]{6}{*}{5} & Co & 0 & $1.32 \pm 0.83$ & $99.81 \%$ \\
\hline & & 5 & $6.31 \pm 1.83$ & \\
\hline & $\mathrm{Ni}$ & 0 & $1.04 \pm 1.92$ & $99.61 \%$ \\
\hline & & 5 & $6.02 \pm 0.18$ & \\
\hline & $\mathrm{Cu}$ & 0 & $2.19 \pm 1.50$ & $115.40 \%$ \\
\hline & & 5 & $7.96 \pm 1.38$ & \\
\hline
\end{tabular}

\subsection{Chelator sorption capacity}

The sorption capacity of a resin is a key factor to estimate the required mass of sorbent resin to achieve quantitative extraction/preconcentration of the elements from a given sample matrix. The calculated sorption capacity (SC) values in $\mathrm{mmol} / \mathrm{g}$ unit for $\mathrm{Co}, \mathrm{Ni}$ and $\mathrm{Cu}$ were shown in 3 replicates at $\mathrm{pH} 6$ and compared with sorption capacity for unmodified AXAD-4 under the same condition as seen in (Figure 5). It is clear from (Figure 5), the sorption capacity for AXAD4-8HQ resin was improved by more than ( $95.90 \%$ for $\mathrm{Co}),(87.13 \%$ for $\mathrm{Ni}$ ) and $(99.28 \%$ for $\mathrm{Cu}$ ) in comparison with the unmodified AXAD-4 for the investigated ions (Vassileva and Furuta, 2003).

The comparison of sorption capacity values of the XAD4$8 \mathrm{HQ}$ chelating resin with other amberlite resins functionalised with 8-HQ chelating agent (Table 1 ) revealed that the XAD4-8HQ chelator exhibits higher sorption values (at least twice) for the investigated metal ions. This finding could be ascribed for the high surface area of XAD- 4 and the efficiency of the chemical functionalisation used in this work.

\subsection{The effect of solution $\mathrm{pH}$}

The $\mathrm{pH}$ of solution plays a significant role in SPE studies because most metal chelating ligands are conjugate bases of weak acids with a very strong tendency for $(\mathrm{H})$ ions. The removal percentage of the studied metals plotted versus $\mathrm{pH}$ as presented in (Figure 6). The maximum sorption for $\mathrm{Co}$ and $\mathrm{Ni}$ were $96.42 \%$ and $97.06 \%$ at $\mathrm{pH} 8$ meanwhile $\mathrm{Cu}$ ion reached its optimal removal percentage (85.76\%) at $\mathrm{pH}$ 
6. The effect of $\mathrm{pH}$ on the sorption of metal ions by immobilized 8-HQ chelator may be influenced by the behavior the chelating agent in the acidic media and basic media, i.e., at low $\mathrm{pH}$ values, the nitrogen of heterocyclic ring of $8-\mathrm{HQ}$ is protonated whilst the phenolic $\mathrm{OH}$ group dissociates in the alkaline environment. Accordingly, the ligand tends to chelate with the metal ions under slightly alkaline conditions because the chance for the formation of more stable complexes is better. Hence, $\mathrm{pH} 8$ is an adequate for the extraction of $\mathrm{Co}, \mathrm{Ni}$ by this chelator, meanwhile $\mathrm{pH} 6$ is optimal to form stable complex with $\mathrm{Cu}$. These $\mathrm{pH}$ values were chosen as optimal in the further experiments (Islam et al., 2010).

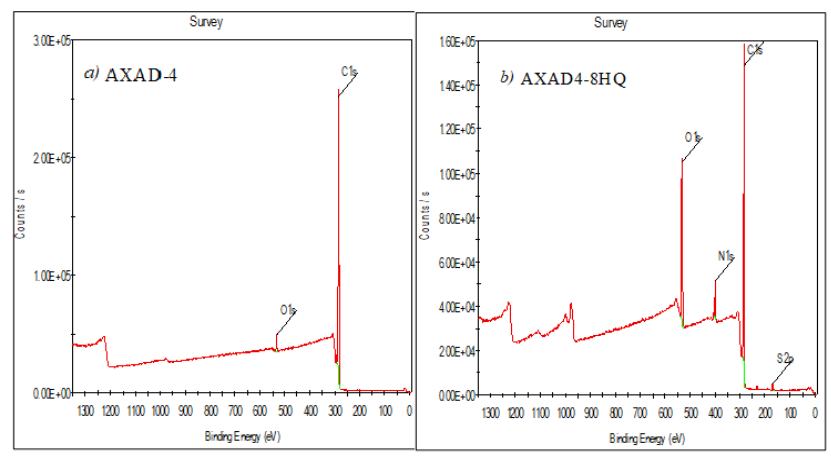

Figure 4. XPS spectra of a) AXAD-4 and b) AXAD4-8HQ resin

\subsection{The effect of contact time}

The effect of contact time is a significant parameter for the quantitative retention of analytes by SPE chelator. The removed percentage of the investigated metal ions as a function of time is shown in (Figure 7). The data represented in (Figure 7) illustrate that the chelating resin uptake $50 \%$ of $\mathrm{Co}$ and $\mathrm{Cu}$ after 10 minutes, however only $27 \%$ of $\mathrm{Ni}$ is removed during this time. However, an equilibration time of 60 minutes was effective for the resin to absorb about $85 \%$ of $\mathrm{Cu}$ and $\mathrm{Co}$, and almost $80 \%$ of $\mathrm{Ni}$ (Xie et al., 2008).

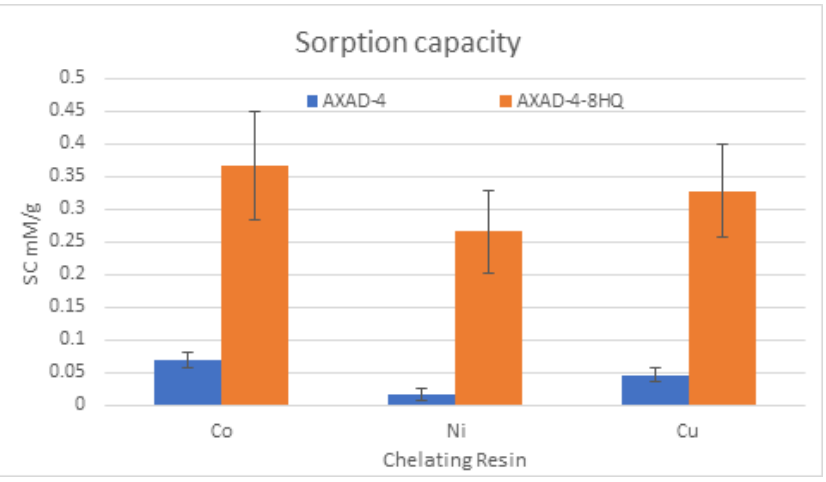

Figure 5. Sorption capacity for XAD-4 and AXAD4-8HQ resin

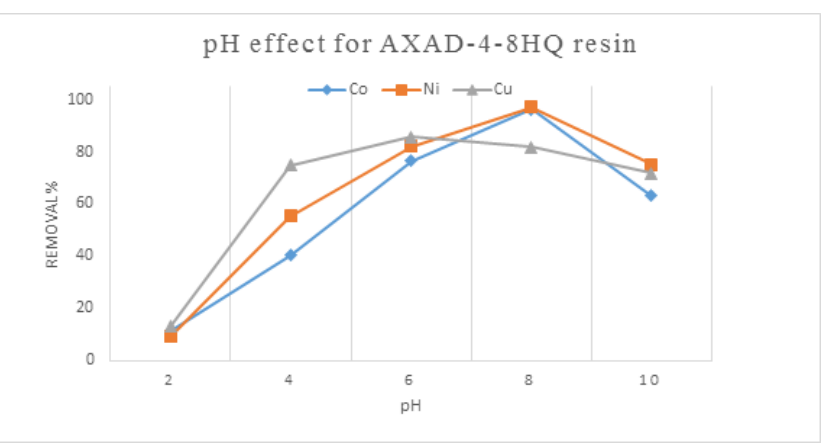

Figure 6. Effect of contact time on the removal of $\mathrm{Co}, \mathrm{Ni}$ and $\mathrm{Cu}$ from Amberlite XAD-4-8HQ resin

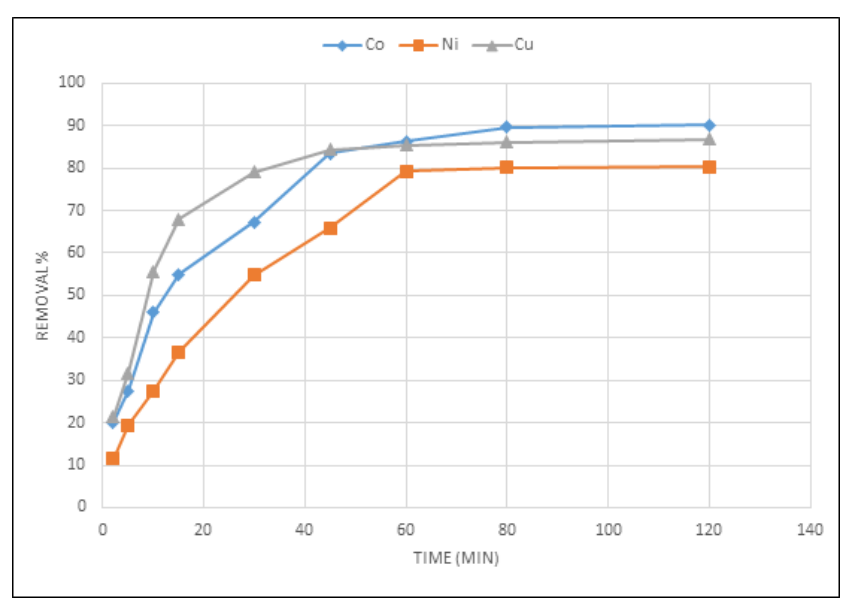

Figure 7. Effect of $\mathrm{pH}$ on the removal of $\mathrm{Co}, \mathrm{Ni}$ and $\mathrm{Cu}$ from Amberlite $X A D-4-8 H Q$ resin

\subsection{Stability and reusability of chelator}

Stability and reusability of SPE materials are viable characteristics to gauge the sustainability and economic efficiency of sorbents. In this article, the chelator stability was evaluated using our previous methods (AISuhaimi, 2019: AlSuhaimi et al., 2019). Briefly, the chelator was treated with acidic and alkaline solutions of different concentrations and its sorption capacity determined for the tested metal ions. The results have shown that the chelator can withstand for concentration of nitric acid up to $3 \mathrm{M} \mathrm{HNO}_{3}$ without exhibiting any significant diminution in the value of sorption capacity (i.e., the maximum reduction is below 2.7\%). However, the treatment of chelating resin with more concatenated acid ( $\geq 4 \mathrm{M} \mathrm{HNO}_{3}$ ), results in a reduction in sorption by about $8 \%$ of the original value. Also, a reddish coloration was observed in solution, which could be ascribed to the detachment of the chelating moieties along with the linkage molecules from the XAD beads. Similarly, the material was soaked in alkaline solution $\mathrm{pH} 12$ (the $\mathrm{pH}$ value adjusted using ammonium solution) and its sorption capacity was tested. Yet, no significant change in sorption capacity being observed. The reusability of the chelating resin has been evaluated by determining its sorption capacity for the investigated metal ions after 50 loading and elution cycles. It was found that there is no substantial change in sorption capacity and hence, it can be reused several times and it is appropriate for dynamic SPE processing. Furthermore, the chelating 
resin show no significant variation in sorption capacity upon storage in the desiccator for more than 8 months in the laboratory.

\subsection{Method Application: The Analysis of Groundwater Real Samples}

The SPE method using the prepared metal chelator has been used for the preparation of groundwater samples prior to the analysis of the selected elements with ICP-MS. The groundwater samples were collected from 5 narrow mouth wells of depth ranged from 130 to $170 \mathrm{~m}$ within Swary valley (upper catchment AlWadi AlMubarak), AlMadina Almonawarah province. The samples $(1 \mathrm{~L})$ were acidified, filtered in field and transported to laboratory in iceboxes (see map in Figure 8).

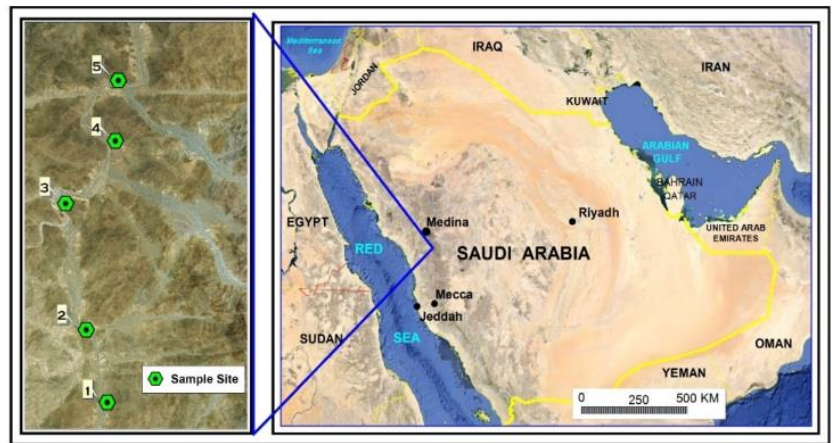

Figure 8. Sampling sites from Swary Valey, AlMadinah AlMunawarah

Prior to the ICP-MS analysis $25 \mathrm{ml}$ of groundwater samples were prepared using SPE protocol described in section 2.8. The concentration of the analyzed metals; $\mathrm{Co}, \mathrm{Ni}$ and $\mathrm{Cu}$, in real samples, along with the recovery for the spiked samples are presented in (Table 2). The recoveries as estimated from the addition of concentrations of spikes to water samples were in the range (96.4\%-99.8\%, 97.8\%99.6\% and $94.4 \%-115.4 \%)$ for $\mathrm{Co}, \mathrm{Ni}$ and $\mathrm{Cu}$ respectively. Thus, the proposed method has proved to be an efficient sample treatment procedure during the simultaneous analysis of trace metals in groundwater real samples.

\section{Conclusion}

The developed chemical modification reported in this article enabled the synthesis of AXAD-4-8HQ metal chelator by aryl radical addition of aniline to the XAD-4 surface followed by diazotization step to couple 8-HQ moieties. ATR-IR, TGA and XPS analysis confirmed the success of resin synthesis. The most important parameters influencing SPE process e.g., the effect of $\mathrm{pH}$ and contact time of metals with sorbent have been investigated. It was found that resin could extracts about 96.42 and $97.06 \%$ of $\mathrm{Co}$ for $\mathrm{Ni}$ at $\mathrm{pH} 8$, and $85.76 \%$ for $\mathrm{Cu}$ at $\mathrm{pH} 6$. Contact time experiments showed that the equilibration time of $60 \mathrm{~min}$ was found to be effective for maximum sorption of $\mathrm{Co}, \mathrm{Ni}$ and $\mathrm{Cu}$. The chelator exhibited relatively higher sorption capacity in comparison with 8-HQ immobilized onto other amberlite substrates using classical nitration/diazotization chemical modifications. Noticeably, although the 60 minutes equilibration time seems to be relatively long, the resin work well as SPE material in dynamic mode using the standard SPE manifold in the examined concentration range. This also has been established by the application of the new metal chelator as an efficient SPE material for sample preparation of trace metals from groundwater real samples of high to moderate salinity.

\section{Acknowledgements}

The authors are grateful for King Abdul-Aziz City for Science \& Technology (KACST) for financial support (grant No: 1-17-01-0060003).

\section{References}

Abiman P., Wildgoose G.G. and Compton R.G. (2008), A mechanistic investigation into the covalent chemical derivatisation of graphite and glassy carbon surfaces using aryldiazonium salts, The Journal of Physical Organic Chemistry, 21, 433-439.

Ahmad A., Siddique J.A., Laskar M.A., Kumar R., Mohd-Setapar S.H., Khatoon A. and Shiekh R.A. (2015), New generation Amberlite XAD resin for the removal of metal ions, Journal of Environmental Sciences, 31, 104-123.

Alqadhi N.F. and Alsuhaimi A.O. (2020), Chemically functionalized activated carbon with 8-hydroxyquinoline using aryldiazonium salts/diazotization route: Green chemistry synthesis for oxins-carbon chelators, The Arabian Journal of Chemistry, 13(1), 1386-1396.

AlSuhaimi A.O. (2019), Preparation of Silica-4-(2-pyridylazo) Resorcinol chelator for solid phase extraction of transition metals from groundwater, Chemical Society of Pakistan, 41(1), 151-160.

AlSuhaimi A.O., AlRadaddi S.M., Al-Sheikh Ali A.K., Shraim A.M. and AlRadaddi T.S. (2019), Silica-based chelating resin bearing dual 8-hydroxyquinoline moieties and its applications for solid phase extraction of trace metal from seawater prior to thier analysis by ICP-MS, The Arabian Journal of Chemistry, 12(3), 360-369.

Armstrong R.D., Todd M., Atkinson J.W. and Scott K. (1996), Selective electrodeposition of metals from simulated waste solutions, The Journal of Applied Electrochemistry, 26, 379384.

Bazrafshan E., Mohammadi L., Ansari-Moghaddam A. and Mahvi A.H. (2015), Heavy metals removal from aqueous environments by electrocoagulation process, Journal of Environmental Health Science \& Engineering, 13, 74.

Brown R.J.C. and Milton M.J.T. (2005), Analytical techniques for trace element analysis, Trends in Analytical Chemistry, 24, 266-274.

Cheira M.F. (2015), Synthesis of pyridylazo resorcinol functionalized Amberlite XAD-16 and its characteristics for uranium recovery, The Journal of Environmental Chemical Engineering, 3, 642-652.

Dabrowski A. (1998), Adsorption and its Applications in Industry and Environmental Protection, Volume 120, Elsevier Science, Amesterdam, Netherlands, pp. 75-275.

Dabrowski A., Hubicki Z., Podkoscielny P. and Robens E. (2004), Selective removal of the heavy metal ions from waters and industrial wastewaters by ion-exchange method, Chemosphere, 56, 91-106.

Duran C., Senturk H.B., Gundogdu A., Eici L., Soylak M., Tufekci M. \& Uycur Y. (2007), Determination of Some Trace Metals in 
Environmental Samples by Flame AAS Following Solid Phase Extraction with Amberlite XAD-2000 Resin after Complexing with 8-Hydroxyquinoline, The Chinese Journal of Chemistry, 25, 196-202

Fan J., Wu C., Wei Y., Peng C. and Peng P. (2007), Preparation of xylenol orange functionalized silica gel as a selective solid phase extractor and its application for preconcentration separation of mercury from waters, Journal of Hazardous Materials, 145, 323-330.

Gao B., Zhang J. and Guo J. (2010), Synthesis of salicylic acidpolystyrene type chelate resin with a new route, Journal of Polymer Research, 17, 301-308.

Gladis J.M. and Rao T.P. (2002), Quinoline-8-ol-immobilized Amberlite XAD-4: Synthesis, characterization, and uranyl ion uptake properties suitable for analytical applications, Analytical and Bioanalytical Chemistry, 373, 867-872.

Golshaei R., Shemirani F. and Davudabadi Farahani M. (2015), Combination of solid phase extraction based on nano alumina and liquid-liquid extraction for selective determination of palladium in food samples, Journal of Analytical Chemistry, 70, 310-315.

Gundogdu A., Duran C., Basri Senturk H., Elci L. \& Soylak M. (2007), imultaneous Preconcentration of Trace Metals in Environmental Samples Using Amberlite XAD-2010/8Hydroxyquinoline System, Acta Chimica Slovenica, 54, 308316

Hu B. and He M. (2012), Pre-concentration and sample treatment techniques for trace element analysis, In: Comprehensive Sampling and Sample Preparation, Pawliszyn J. (ed.), Elsevier Inc., Amesterdam, Netherlands, pp. 367-390.

Huck C.W. and Bonn G.K. (2000), Recent developments in polymer-based sorbents for solid-phase extraction, Journal of Chromatography A, 885, 51-72.

Islam A., Laskar M.A. and Ahmad A. (2010), Characterization and application of 1- (2-pyridylazo) -2-naphthol functionalized amberlite XAD-4 for preconcentration of trace metal ions in real matrices, Journal of Chemical \& Engineering Data, 55535561.

Jung K.H., Byun J.H., Lee Y.S. and Park S.J. (2010), Synthesis and characterization of chemically modified polystyrene as processable carbon fiber precursors, Research on Chemical Intermediates, 36, 621-627.

Kempegowda R.G. and Malingappa P. (2013), Diazonium functionalized exfoliated graphitic carbon as a binderless and covalently modified electrochemical interface for mercury sensing, Sensors \& Actuators, B: Chemical, 186, 478-485.

Khan M.S., Zaidi A., Goel R. and Musarrat J. (2011), Biomanagement of Metal-Contaminated Soils, Springer Science, Heidelberg, Germany, pp. 183-323.

Korn M.D.G.A., De Andrade J.B., De Jesus D.S., Lemos V.A., Bandeira M.L.S.F., Dos Santos W.N.L. and Ferreira S.L.C. (2006), Separation and preconcentration procedures for the determination of lead using spectrometric techniques, Talanta, 69, 16-24.

Kosa S.A., Al-Zhrani G. and Abdel Salam M. (2012), Removal of heavy metals from aqueous solutions by multi-walled carbon nanotubes modified with 8-hydroxyquinoline, Chemical Engineering, 181-182, 159-168.

Lee M.D.W., Eum C.H., Lee I.H. \& Jeon S.J. (1988), Adsorption Behavior of 8-Hydroxyquinoline and Its on Amberlite XAD
Resins, and Adsorption of Metal Using Chelating AgentImpregnated Resins, Analytical Sciences, 4, 505-510.

Lichtfouse E., Schwarzbauer J. and Robert D. (2013), Green Materials for Energy, Products and Depollution, Springer Science, Dordrecht, Germany, pp. 151-228.

Liu R., Ruan T., Wang T., Song S., Guo F. and Jiang G. (2014), Determination of nine benzotriazole UV stabilizers in environmental water samples by automated on-line solid phase extraction coupled with high-performance liquid chromatography-tandem mass spectrometry, Talanta, 120, 158-166.

Liu Y., Guo Y., Chang X., Meng S., Yang D. and Din B. (2004), Column Solid-Phase Extraction with 2Acetylmercaptophenyldiazoaminoazobenzene (AMPDAA) Impregnated Amberlite XAD-4 and Determination of Trace Heavy Metals in Natural Waters by Flame Atomic Absorption Spectrometry, Microchimica Acta, 149, 95-101.

Liu Y., Guo Y., Meng S. and Chang X. (2007), Online separation and preconcentration of trace heavy metals with 2,6dihydroxyphenyl-diazoaminoazobenzene impregnated amberlite XAD-4, Microchimica Acta, 158, 239-245.

Mendil D., Karatas M. and Tuzen M. (2015), Separation and preconcentration of $\mathrm{Cu}(\mathrm{II}), \mathrm{Pb}$ (II), $\mathrm{Zn}$ (II), $\mathrm{Fe}(\mathrm{III})$ and $\mathrm{Cr}$ (III) ions with coprecipitation method without carrier element and their determination in food and water samples, Food Chemistry, 177, 320-324.

Nezhati M.N., Panahi H.A., Moniri E., Kelahrodi S.R., Assadian F. and Karimi M. (2010), Synthesis, characterization and application of allyl phenol modified amberlite XAD-4 resin for preconcentration and determination of copper in water samples, Korean Journal of Chemical Engineering, 27, 12691274.

Nickerson B. (2011), Sample Preparation of Pharmaceutical Dosage Forms: Challenges and Strategies for Sample Preparation and Extraction, Springer Science, Heidelberg, Germany, pp. 43-345.

Pacurariu C., Mihoc G., Popa A., Muntean S.G. and lanos R. (2013), Adsorption of phenol and $p$-chlorophenol from aqueous solutions on poly (styrene-co-divinylbenzene) functionalized materials, Chemical Engineering, 222, 218-227.

Pandurangappa M. and Raghu G.K. (2011), Chemically Modified Carbon Nanotubes: Derivatization and their Applications, Intech Open Access publisher, pp. 500-522.

Sadia M., Jan M.R., Shah J. \& Haq A. (2016), Comparison of simple and chelated amberlite IR-120 for preconcentration and Determination of $\mathrm{Cu}(\mathrm{II})$ from aqueous samples, Bulletin of the Chemical Society of Ethiopia, 30(1),39-54.

Saxena R. and Meena P.L. (2014), Flow injection online solid phase extraction system using Amberlite XAD-16 functionalized with 8-hydroxyquinoline for copper and zinc determination by flame atomic absorption spectrometry, RSC Advances, 4, 20216-20225.

Saylam A., Seferoğlu Z. and Ertan N. (2014), Azo-8hydroxyquinoline dyes: The synthesis, characterizations and determination of tautomeric properties of some new phenyland heteroarylazo-8-hydroxyquinolines, Journal of Molecular Liquids, 195, 267-276.

Scheuerman R.A. and Tumelty D. (2000), The reduction of aromatic nitro groups on solid supports using sodium hydrosulfite $\left(\mathrm{Na}_{2} \mathrm{~S}_{2} \mathrm{O}_{4}\right)$, Tetrahedron Letters, 41, 6531-6535. 
Shemirani F. and Yousefi S.R. (2007), Selective extraction and preconcentration of cerium(IV) in water samples by cloud point extraction and determination by inductively coupled plasma optical emission spectrometry, Microchimica Acta, 157, 223-227.

Soylak M., Divrikli U., Saracoglu S. and Elci L. (2007), Membrane filtration - Atomic absorption spectrometry combination for copper, cobalt, cadmium, lead and chromium in environmental samples, Environmental Monitoring and Assessment, 127, 169-176.

Srivastava S. and Goyal P. (2010), Novel Biomaterials Decontamination of Toxic Metals from Wastewater, SpringerVerlag, Berlin, Germany, pp. 111-122.

Uzun A., Soylak M. and Elci L. (2001), Preconcentration and separation with Amberlite XAD-4 resin ; determination of $\mathrm{Cu}$, $\mathrm{Fe}, \mathrm{Pb}, \mathrm{Ni}, \mathrm{Cd}$ and $\mathrm{Bi}$ at trace levels in waste water samples by flame atomic absorption spectrometry, Talanta, 54, 197-202.

Vassileva E. and Furuta N. (2003), Application of iminodiacetate chelating resin muromac $\mathrm{A}-1$ in on-line preconcentration and inductively coupled plasma optical emission spectroscopy determination of trace elements in natural waters, Spectrochimica Acta Part B, 58, 1541-1552.

Wang J., Hansen E.H. and Miró M. (2003), Sequential injectionbead injection-lab-on-valve schemes for on-line solid phase extraction and preconcentration of ultra-trace levels of heavy metals with determination by electrothermal atomic absorption spectrometry and inductively coupled plasma mass, Analytica Chimica Acta, 499, 139-147.

Wegscheider W. and Knapp G. (1981), Preparation of chemically modified cellulose exchangers and their use for the preconcentration of trace elements, Critical Reviews in Analytical Chemistry 11, 79-102.

Wildgoose G.G., Leventis H.C., Davies I.J., Crossley A., Lawrence N.S., Jiang L., Compton R.G. (2005), Graphite powder derivatised with poly- L -cysteine using "building-block" chemistry - a novel material for the extraction of heavy metal ions, Journal of Materials Chemistry, 15, 2375-2382.

Xie F., Lin X., Wu X. and Xie Z. (2008), Solid phase extraction of lead (II), copper (II), cadmium (II) and nickel (II) using gallic acid-modified silica gel prior to determination by flame atomic absorption spectrometry, Talanta, 74, 836-843.

Zhai Y., Duan S., He Q., Yang X. and Han Q. (2010), Solid phase extraction and preconcentration of trace mercury(II) from aqueous solution using magnetic nanoparticles doped with 1,5-diphenylcarbazide, Microchimica Acta, 169, 353-360.

Zhao R.-S., Hu C., Zhou J.-B., Yuan J.-P., Wang S.-S. and Wang X. (2011), Preconcentration and sensitive determination of hexabromocyclododecane diastereomers in environmental water samples using solid phase extraction with bamboo charcoal cartridge prior to rapid resolution liquid chromatography - electrospray tandem mass spec, Analytical and Bioanalytical Chemistry, 400, 1189-1195. 